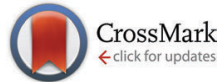

Cite this: J. Mater. Chem. C, 2015, 3, 3790

Received 29th December 2014, Accepted 2nd March 2015

DOI: $10.1039 / c 4 t c 02977 a$

www.rsc.org/MaterialsC

\title{
Cholesteric films exhibiting expanded or split reflection bands prepared by atmospheric photopolymerisation of diacrylic nematic monomer doped with a photoresponsive chiral dopant
}

\author{
Y. Harada, K. Sakajiri, H. Kuwahara, S. Kang, J. Watanabe and M. Tokita*
}

\begin{abstract}
Cholesteric liquid crystal (CLC) films with gradient pitches are prepared by atmospheric UV irradiation of mixtures of a diacrylic nematic monomer (M), a macrocyclised chiral cinnamate dimer (CD), and a photoinitiator (PI). UV light induces the intramolecular photodimerisation of the two cinnamate moieties in the CD to decrease the helical twisting power. The CLC of 90/10 (w/w) mixture of M/CD exhibits an optical pitch of $482 \mathrm{~nm}$, which increases homogeneously to $815 \mathrm{~nm}$ upon atmospheric UV irradiation of the film. When the CLC doped with $1.5 \mathrm{wt} \% \mathrm{PI}$ is formed into a planar-aligned film and irradiated with UV light in the atmosphere, the CLC film exhibits pitches that increases toward the air-interface side so as to result in a wide reflection band ranging from 420 to $890 \mathrm{~nm}$; in addition, the film assumes a silver appearance. When the PI concentration and UV intensity are increased, the spectra of the CLC films exhibit two reflection bands and films assume a magenta colour. Such pitch distributions result from the confliction between untwisting and polymerisation of the CLC, both of which are induced by the UV light, although the polymerisation rate is decreased by the diffusion of atmospheric oxygen into the film.
\end{abstract}

\section{Introduction}

Cholesteric liquid crystals (CLCs) consist of molecules whose orientation varies in a helical fashion with a twist axis perpendicular to the local director. At normal incidence, they reflect circularly polarised incident light of the same handedness as the cholesteric helix and of wavelength $\lambda$ between $n_{\mathrm{o}} P$ and $n_{\mathrm{e}} P$, where $n_{\mathrm{o}}$ and $n_{\mathrm{e}}$ are the ordinary and extraordinary refractive indices, respectively, of the locally uniaxial structure and $P$ is the pitch of the helix. Thus, the reflection bandwidth $\Delta \lambda$ is given by $\Delta \lambda=\Delta n P$, where $\Delta n=n_{\mathrm{e}}-n_{\mathrm{o}}$ is the birefringence. Because $\Delta n$ is typically limited to $0.3-0.4$ for colorless organic compounds, CLCs typically exhibit a $\Delta \lambda$ of less than $150 \mathrm{~nm}$ in the visible spectrum. Although a narrow reflection band is desirable for applications such as optical filters and thermal imaging, ${ }^{1-4}$ it becomes a drawback in other applications, such as reflective displays, broadband circular polarizers, and switchable mirrors. ${ }^{5-8}$

One of the subtle approaches to enlarging the reflection band of CLCs is the formation of a pitch gradient. ${ }^{9}$ Gradients in

Department of Organic and Polymeric Materials, Tokyo Institute of Technology, Ookayama, Meguro-ku, Tokyo 152-8552, Japan.

E-mail: mtokita@polymer.titech.ac.jp the pitch have been created by the following three methods. The first method is annealing two CLC films with long and short pitches in tight contact. ${ }^{10}$ A continuous pitch gradient is formed between the two original films because of thermal diffusion of the LC molecules. The second method is the effective utilization of photoracemisation ${ }^{11}$ or photoisomerisation ${ }^{12}$ of chiral dopants. Photoracemization converts the $(R)$-enantiomer of a dopant near the UV-irradiated CLC film surface to the corresponding $(S)$-enantiomer. The enantiomers diffuse mutually across the film to generate a pitch gradient. The photoisomerisation of chiral dopant increases/decreases the helical twisting power (HTP). When a CLC is doped with a UV absorber, the isomerisation at the lamp side of the film proceeds faster than that at the opposite site. Thus, the film possesses a pitch gradient after a certain period of UV exposure. The third method is photopolymerisation of a planar-oriented CLC film of a mixture of cholesteric diacrylate monomer and nematic monoacrylate monomer in the presence of a photoinitiator (PI). ${ }^{6-8,13}$ Whereas the more reactive diacrylic chiral monomer polymerise preferentially, the nematic acrylate monomer diffuse toward the sides opposite the irradiated surface. Thus, the concentration gradient of the helix-winding chiral material is produced and the pitch varies continuously over the film thickness. The $\Delta \lambda$ of the film is increased, and the reflection band can be broadened over the entire visible spectrum. 
In this paper, we demonstrate that gradient-pitch CLC films can be prepared by atmospheric UV-light irradiation on a planaraligned CLC of a mixture of a diacrylic nematic monomer and a photoreactive chiral cinnamate dimer in the presence of a PI. UV light causes the intramolecular photodimerisation of the two cinnamate moieties in the dimer to decrease the HTP, and it simultaneously induces polymerisation of the nematic diacrylate monomer via a free-radical cross-linking mechanism and fixes the conformation of the LC phase. As oxygen diffusing into the film decreases the radical polymerisation rate, competition between the rates of monomer polymerisation and the chiral dopant photoreaction makes the pitch increase continuously from the glass-substrate side to the air-interface side. The deposited CLC film exhibited a wide reflection bandwidth to assume a silver color. Moreover, with increasing UV intensity and PI concentration, two reflection bands formed in the CLC film, which assumed a magenta colour.

\section{Experimental}

\section{Materials}

The diacrylate nematic liquid crystal (NLC) monomer LC242 (BASF) and the radical polymerisation PI Irg907 (BASF) were used. The chiral dopant C8-4-2Me was synthesized using methods similar to that described in the literature. ${ }^{14}$ The structure formulas of these chemicals are shown in Fig. 1.

Fig. 2 outlines the synthetic route leading to C8-4-2Me. A mixture of 3-(4-hydroxyphenyl)acrylic acid (1.64 g, $10 \mathrm{mmol}$ ), 5-bromopent-1-ene $(2.24 \mathrm{~g}, 15 \mathrm{mmol})$, potassium hydroxide $(\mathrm{KOH})$ (1.12 g, $20 \mathrm{mmol})$, potassium iodide (KI) (0.58 g, $5 \mathrm{mmol})$, ethanol $(\mathrm{EtOH})(60 \mathrm{ml})$, and water $(20 \mathrm{ml})$ was refluxed for $24 \mathrm{~h}$. The solution was cooled and poured into $400 \mathrm{ml}$ of water and the resulting precipitate was collected by filtration and washed with water. The crude product was recrystallised from ethanol to give $1(2.23 \mathrm{~g}, 96 \%)$ as a white solid. ${ }^{1} \mathrm{H}-\mathrm{NMR}\left(400 \mathrm{MHz}, \mathrm{CDCl}_{3}\right): \delta=7.75(1 \mathrm{H}, \mathrm{d}, J=15.8 \mathrm{~Hz}$, Ar-CH), 7.50 (2H, d, $J=8.8 \mathrm{~Hz}, \mathrm{Ar}-\mathrm{H}), 6.91(2 \mathrm{H}, \mathrm{d}, J=8.8 \mathrm{~Hz}, \mathrm{Ar}-\mathrm{H})$,
$6.32(1 \mathrm{H}, \mathrm{d}, J=15.8 \mathrm{~Hz}, \mathrm{CO}-\mathrm{CH}), 5.90-5.80\left(1 \mathrm{H}, \mathrm{m}, \mathrm{CH}_{2} \mathrm{CH}\right)$, 5.10-5.04 (1H, m, = $\left.\mathrm{CH}_{2}\right), 5.03-5.00\left(1 \mathrm{H}, \mathrm{m},=\mathrm{CH}_{2}\right), 4.02(2 \mathrm{H}, \mathrm{t}$, $\left.J=6.6 \mathrm{~Hz}, \mathrm{OCH}_{2}\right), 2.25\left(2 \mathrm{H}, \mathrm{m},=\mathrm{CHCH}_{2}\right), 1.91(2 \mathrm{H}, \mathrm{m}$, $\mathrm{CH}_{2} \mathrm{CH}_{2} \mathrm{CH}_{2}$ ).

A mixture of 1 (3.48 g, $15 \mathrm{mmol}$ ), (S)-2-methylbutane-1,4-diol (0.52 g, $5.0 \mathrm{mmol}$ ), 1-ethyl-3-(3-dimethylaminopropyl)carbodiimide (EDCI) (3.8 g, $20 \mathrm{mmol}$ ), $\mathrm{N}, \mathrm{N}$-dimethyl-4-aminopyridine (DMAP) (0.24 g, $2.0 \mathrm{mmol})$ and dichloromethane $\left(\mathrm{CH}_{2} \mathrm{Cl}_{2}\right)(100 \mathrm{ml})$ was stirred at r.t. for $12 \mathrm{~h}$. The solvent was removed under reduced pressure and poured into methanol. The precipitate was collected by filtration and recrystallised from a mixed solvent of chloroform $\left(\mathrm{CHCl}_{3}\right)$ and EtOH to give $2(2.56 \mathrm{~g}, 96 \%)$ as a white solid. ${ }^{1} \mathrm{H}$ NMR $\left(400 \mathrm{MHz}, \mathrm{CDCl}_{3}\right): \delta=7.64(2 \mathrm{H}, \mathrm{d}, J=15.8 \mathrm{~Hz}, \mathrm{Ar}-\mathrm{CH}), 7.47-7.44$ (4H, m, Ar-H), 6.88 (4H, d, $J=8.5 \mathrm{~Hz}, \mathrm{Ar}-\mathrm{H},), 6.34-6.28(2 \mathrm{H}, \mathrm{m}$, $\mathrm{O}=\mathrm{CCH}), 5.90-5.80\left(2 \mathrm{H}, \mathrm{m}, \mathrm{CH}_{2}=\mathrm{CH}\right), 5.09-5.00\left(4 \mathrm{H}, \mathrm{m},=\mathrm{CH}_{2}\right)$, 4.35-4.24 (2H, m, OCH $\left.\left.\mathrm{OH}_{2} \mathrm{CH} \mathrm{CH}_{3}\right)\right), 4.11-4.10\left(2 \mathrm{H}, \mathrm{m}, \mathrm{CH}_{2} \mathrm{CH}_{2}-\right.$ $\left.\mathrm{CH}\left(\mathrm{CH}_{3}\right)\right), 3.99\left(4 \mathrm{H}, \mathrm{t}, J=6.6 \mathrm{~Hz}, J=6.3 \mathrm{~Hz}, \mathrm{ArOCH}_{2}\right), 2.27-2.22$ $\left(4 \mathrm{H}, \mathrm{m},=\mathrm{CHCH}_{2}\right), 2.12-2.04\left(2 \mathrm{H}, \mathrm{m}, \mathrm{CH}\left(\mathrm{CH}_{3}\right) \mathrm{CH}_{2} \mathrm{CH}_{2}\right), 1.93-$ $1.86\left(4 \mathrm{H}, \mathrm{m}, \mathrm{CH}_{2} \mathrm{CH}_{2} \mathrm{CH}_{2}\right), 1.67-1.58\left(1 \mathrm{H}, \mathrm{m}, \mathrm{CH}_{3} \mathrm{CH}\right), 1.06(3 \mathrm{H}$, $\left.\mathrm{d}, J=6.8 \mathrm{~Hz}, \mathrm{CH}_{3}\right)$.

A mixture of $2(1.07 \mathrm{~g}, 2.0 \mathrm{mmol})$, first-generation Grubbs catalyst $(0.33 \mathrm{~g}, 0.40 \mathrm{mmol})$ and dry $\mathrm{CH}_{2} \mathrm{Cl}_{2}(2.0 \mathrm{~L})$ was stirred at r.t. for $3 \mathrm{~d}$. The solvent was removed under reduced pressure. The residue was purified by alumina column chromatography with $\mathrm{CH}_{2} \mathrm{Cl}_{2}$ as the eluent and by recycle HPLC and was subsequently recrystallised from a mixed solvent of $\mathrm{CHCl}_{3}-$ $\mathrm{MeOH}$ to give $\mathrm{C} 8-4-2 \mathrm{Me}(3,1.01 \mathrm{~g}, 65 \%)$ as a white solid. ${ }^{1} \mathrm{H}$ NMR (400 $\left.\mathrm{MHz}, \mathrm{CDCl}_{3}\right): \delta=7.58-7.48(2 \mathrm{H}, \mathrm{m}, \mathrm{Ar}-\mathrm{CH})$, 7.25-7.18 (4H, m, Ar-H), 6.67-6.57 (4H, m, Ar-H), 6.25-6.17 $(2 \mathrm{H}, \quad \mathrm{m}, \mathrm{O}=\mathrm{CCH}), \quad 5.45-5.38 \quad(2 \mathrm{H}, \quad \mathrm{m}, \quad \mathrm{CH}=\mathrm{CH}), \quad 4.46-$ 4.41(1H, m, $\left.\mathrm{OCH}_{2} \mathrm{CH}\left(\mathrm{CH}_{3}\right)\right), 4.35-4.31\left(1 \mathrm{H}, \mathrm{m}, \mathrm{CH}_{2} \mathrm{CH}_{2} \mathrm{CH}\left(\mathrm{CH}_{3}\right)\right)$, 4.20-4.14 (1H, m, $\left.\mathrm{CH}_{2} \mathrm{CH}_{2} \mathrm{CH}\left(\mathrm{CH}_{3}\right)\right), 3.89-3.80(4 \mathrm{H}+1 \mathrm{H}, \mathrm{m}$, $\left.\mathrm{ArOCH}_{2}, \mathrm{OCH}_{2} \mathrm{CH}\left(\mathrm{CH}_{3}\right)\right)$, 2.29-2.17 (4H, m, $\left.=\mathrm{CHCH}_{2}\right), 2.14-$ $2.06\left(1 \mathrm{H}, \mathrm{m}, \mathrm{CH}\left(\mathrm{CH}_{3}\right) \mathrm{CH}_{2} \mathrm{CH}_{2}\right), 1.97-1.82(4 \mathrm{H}+1 \mathrm{H}, \mathrm{m}$, $=\mathrm{CHCH}_{2} \mathrm{CH}_{2}, \mathrm{CH}\left(\mathrm{CH}_{3}\right) \mathrm{CH}_{2} \mathrm{CH}_{2}$,), 1.67-1.62 (1H, m, $\left.\mathrm{CH}_{3} \mathrm{CH}\right)$, $1.03\left(3 \mathrm{H}, \mathrm{d}, J=6.84 \mathrm{~Hz}, \mathrm{CH}_{3}\right) .3$ was obtained as a mixture of the cis and trans isomers, however, the accurate isomer ratio was hardly estimated by the NMR spectrum showing peaks of each<smiles>C=CC(=O)OCCCCOC(=O)Oc1ccc(C(=O)Oc2ccc(OC(=O)c3ccc(OC(=O)OCCCCOC(=O)C=C)cc3)c(C)c2)cc1</smiles>

LC242<smiles>CSc1ccc(C(=O)C(C)(C)N2CCOCC2)cc1</smiles>

$\operatorname{lrg} 907$

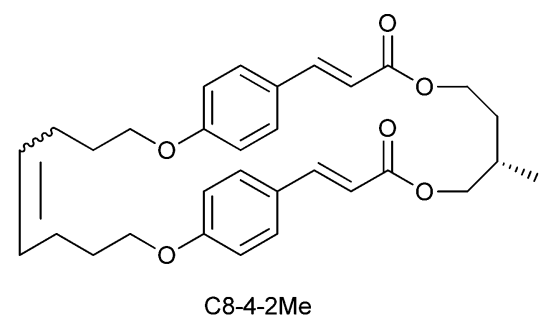

Fig. 1 Chemical structures of the mesogenic compound (LC242), the photoinitiator (PI), and the photoreactive chiral dopant (C8-4-2Me). 
<smiles>O=C(O)/C=C/c1ccc(O)cc1</smiles><smiles>C=CC(C)(Br)Br</smiles><smiles>C=CCOc1ccc(/C=C/C(=O)O)cc1</smiles><smiles>C[C@@H](CO)CCO</smiles><smiles>C=CC(C)(C)Oc1ccc(/C=C/C(=O)OCC[C@@H](C)COC(=O)/C=C/c2ccc(OC(C)(C)C=C)cc2)cc1</smiles>

Grubbs cat. 1st $\mathrm{CH}_{2} \mathrm{Cl}_{2}$<smiles></smiles>

3, $\mathrm{C} 8-4-2 \mathrm{Me}$

Fig. 2 Synthesis of C8-4-2Me.

isomer overlapping with each other. MS(MALDI-TOF) for $\mathrm{C}_{31} \mathrm{H}_{36} \mathrm{O}_{6}: 527.19\left(\mathrm{M}+\mathrm{Na}^{+}\right)$.

\section{LC film preparation}

Planar-aligned CLC films with a thickness of $20 \mu \mathrm{m}$ were prepared by spreading a CLC solution in chloroform at a concentration of $10 \mathrm{wt} \%$ onto a rubbed polyimide-coated glass. The LC films were irradiated with UV light from the air-interface side using an Ushio Spot UV curing SP-9 $\left(\lambda_{\max }=365 \mathrm{~nm}\right)$ light source equipped with band-pass filter (365 nm). The film temperature was controlled using a Mettler FP90/82HT hotstage.

\section{Physical measurements}

Transmission spectra were measured on a Nikon lv100 POL polarising optical microscope equipped with an Ocean Optics USB4000 spectroscope. To measure the transmission of circularly polarised light, an achromatic $\lambda / 4$ film was inserted between the CLC film and the polarizer. The reflection was measured as transmission loss. Scanning electron microscopy (SEM) was performed on a JEOL JSM-7000F microscope.

\section{Results and discussion}

CLCs were prepared by doping LC242 with C8-4-2Me. C8-4-2Me is a macrocyclised chiral dimer consisting of two photoreactive cinnamate moieties that are linked to each other by a flexible spacer with a chiral carbon on one side and an alkyl spacer on the other side. UV irradiation of macrocyclised chiral cinnamate dimers induced intramolecular [2+2] dimerisation of the cinnamate groups to decrease the HTP. ${ }^{14}$ Though C8-4-2Me in the LC242 nematic LC exhibited the HTP of $21 \mu^{-1} \mathrm{wt}^{-1}$, the HTP of the photoreacted C8-4-2Me measured for a sample recovered after complete photodimerisation in solution was $0 \mu \mathrm{m}^{-1} \mathrm{wt} \%^{-1}$. A 90/10 (w/w) mixture of LC242/C8-4-2Me formed a CLC. Fig. 3a shows the transmission spectra of the resulting CLC films with a thickness $20 \mu \mathrm{m}$ under irradiation with UV light $\left(10 \mathrm{~mW} \mathrm{~cm}{ }^{-2}\right.$, $\lambda_{\text {max }}=365 \mathrm{~nm}$ ) for periods ranging from 0 to $150 \mathrm{~s}$. The film temperature was maintained at $70{ }^{\circ} \mathrm{C}$ during the UV irradiation and the spectrum measurements. Before UV irradiation, the CLC film exhibited a reflection band with a center wavelength $\lambda_{0}=482 \mathrm{~nm}$. When the UV irradiation period was increased to $150 \mathrm{~s}$, the $\lambda_{0}$ increased to $815 \mathrm{~nm}$. In Fig. 3b, the long- and short-edge wavelengths ( $\lambda_{\mathrm{L}}$ and $\lambda_{\mathrm{S}}$, respectively) are plotted against the irradiation time. Here the reflection band edge wavelengths are defined as the wavelengths at half-maxima. Both $\lambda_{\mathrm{L}}$ and $\lambda_{\mathrm{S}}$ increased linearly with increasing irradiation period, although the peak widths, $\Delta \lambda$, doubled; this result was as expected on the basis of the increase in $P$ being similar to that reported for a CLC of a mixture of a chiral cinnamate dimer and an inactive NLC. ${ }^{14}$ Thus, the UV light passes through the film and decreases the HTP of the C8-4-2Me chiral dopant so as to increase $P$ homogeneously.

When the CLC was doped with Irg907, UV irradiation induced the polymerisation of LC242 as well as the photoreaction (a)

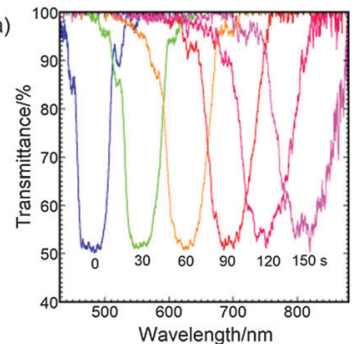

(b)

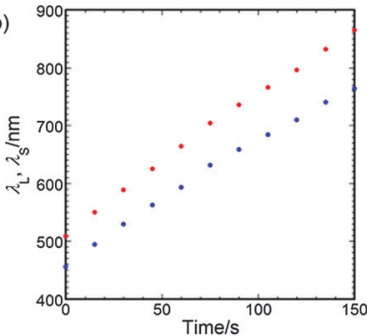

Fig. 3 Effects of UV-irradiation time on the (a) transmission spectrum and the (b) reflection band edge wavelengths for the chiral nematic liquid crystal of a 90/10 (w/w) mixture of LC242/C8-4-2Me. 
of C8-4-2Me. Here, PI-doped CLC of a $(90-x) / 10 / x(\mathrm{w} / \mathrm{w} / \mathrm{w})$ mixture of LC242, C8-4-2Me and Irg907 is designated as CLC- $x$. Fig. 4a shows the transmission spectrum of the CLC-2.5 films subjected to UV irradiation for periods up to $150 \mathrm{~s}$. The spectrum of the film before UV irradiation exhibited a reflection band with $\lambda_{0}=485 \mathrm{~nm}$ and $\Delta \lambda=59 \mathrm{~nm}$. After the film was subjected to UV irradiation, the reflection band expanded significantly. The $\lambda_{\mathrm{L}}$ and $\lambda_{\mathrm{S}}$ of the PI-containing CLC film are plotted against the irradiation time in Fig. $4 \mathrm{~b}$. Whereas $\lambda_{\mathrm{S}}$ decreased slightly from $455 \mathrm{~nm}$ to $444 \mathrm{~nm}, \lambda_{\mathrm{L}}$ increased significantly from $515 \mathrm{~nm}$ to $652 \mathrm{~nm}$, and $\Delta \lambda$ increased to $208 \mathrm{~nm}$. When $x$ was decreased to $1.5 \mathrm{wt} \%$ and the UV irradiation period was prolonged to $300 \mathrm{~s}$ to ensure vitrification of the film, $\lambda_{\mathrm{L}}$ increased from 513 to $871 \mathrm{~nm}$, whereas $\lambda_{\mathrm{S}}$ decreased slightly from 457 to $432 \mathrm{~nm}$ (Fig. 5a). The spectrum of the UV-irradiated CLC-1.5 film exhibited a wide reflection band ranging from 420 to $890 \mathrm{~nm}$ and the film itself exhibited a silver sheen, as shown in the inset photograph in Fig. 5a. UV-irradiated CLC- $x$ films with $x$ less than 1 wt $\%$ exhibited a sticky surface even after prolonged UV irradiation.
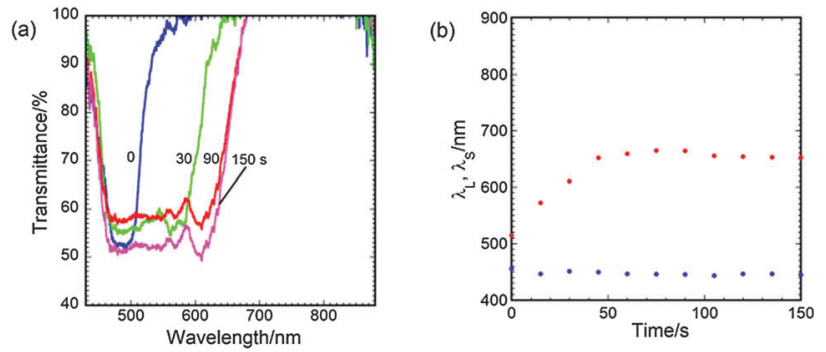

Fig. 4 Effects of UV-irradiation time on the (a) transmission spectrum and (b) reflection band edge wavelengths for CLC-2.5. The UV light intensity was $10 \mathrm{~mW} \mathrm{~cm}^{-2}$.

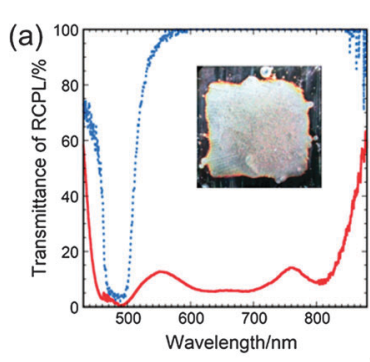

(c)

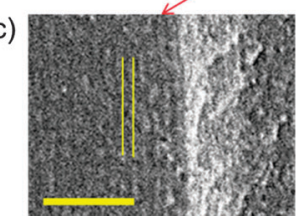

(b)

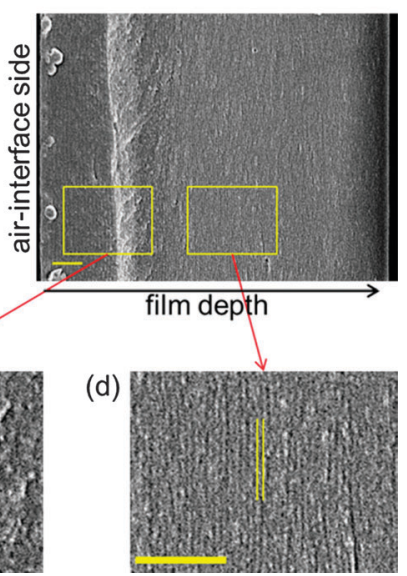

Fig. 5 (a) Transmission of right-handed circularly polarized light by CLC-1.5 before (broken line) and after (solid line) irradiation with UV light $\left(10 \mathrm{~mW} \mathrm{~cm}{ }^{-2}, 300 \mathrm{~s}\right)$. The inset shows the appearance of the film whose transmission spectrum is shown by the solid line. (b) SEM image of the cross-section of the UV-irradiated CLC-1.5 film. Scale bar: $2 \mu \mathrm{m}$. Two rectangular areas enclosed with lines in left and right sides are magnified and shown in (c) and (d), respectively. In (c) and (d), vertical thin lines are guide to eye. Scale bar: $2 \mu \mathrm{m}$.
The broadening of the reflection band of CLC- $x$ films by UV irradiation is attributed to the formation of a pitch gradient in the film thickness direction. The scanning electron microscopy (SEM) image of the cross-section of the UV-irradiated CLC-1.5 film shown in Fig. 5b includes numerous lines parallel to the film direction. Two areas in the SEM image at different film depths are magnified and shown in Fig. $5 c$ and d. The line spacing decreases from 275 to $150 \mathrm{~nm}$ from the air-interface side to the glass-substrate side. Because this line spacing corresponds to half of $P$, it indicates that $P$ decreases from $550 \mathrm{~nm}$ at the interface with air to $300 \mathrm{~nm}$ at a film depth of $10 \mu \mathrm{m}$. The optical pitch $n P$ is plotted against film depth as open circles in Fig. 6 a under the assumption that the refractive index of the CLC is a typical value of 1.5. The $n P$ decreases in two stages with increasing film depth (i.e., the distance from the air surface) to a depth of $10 \mu \mathrm{m}$. The $n P$ decreases from 830 to $700 \mathrm{~nm}$ and from 700 to $450 \mathrm{~nm}$ at film depths ranging from 0 to $2 \mu \mathrm{m}$ and from 5 to $10 \mu \mathrm{m}$, respectively, whereas $n P$ is constant at film depths between 2 to $5 \mu \mathrm{m}$ and greater than $10 \mu \mathrm{m}$. Such a variation of $n P$ appears to correspond to the reflection spectrum. The wide reflection band of CLC-1.5 has two hollows at 550 and $760 \mathrm{~nm}$ and can be divided into two narrower bands $\left(\lambda_{0}=475\right.$ and $\left.805 \mathrm{~nm}\right)$ and one wider band $\left(\lambda_{0}=\right.$ $655 \mathrm{~nm})$. The wider band is associated with the second $n P$ decrease at film depths ranging from 5 to $10 \mu \mathrm{m}$.

The gradating cholesteric pitch formation can result from a conflict between helix untwisting and the polymerisation of the diacrylate monomer in the CLC, both of which are induced by UV light. UV light induces the photoreaction of the chiral dopant, which decreases the HTP to untwist the CLC; however, it also induces polymerisation of the diacyclic monomer to prevent the CLC from changing conformation, such as by untwisting. The $P$ at film depth greater than $10 \mu \mathrm{m}$ is approximately the same as that in the non-UV-irradiated film, indicating that the CLC vitrifies so quickly that it cannot untwist even though the HTP of the chiral dopant decreases. In the upper half of the film, the pitch increases toward the air-interface side, suggesting that the CLC vitrified after partial unwinding of the CLC helix. The gradual pitch increment indicates that the polymerisation rate slows toward the air-interface side. Such a (a)

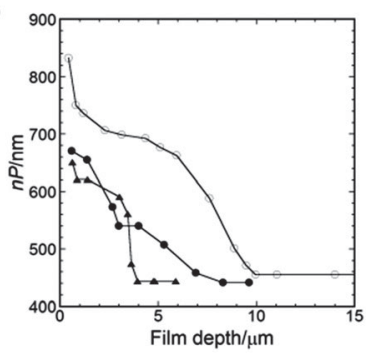

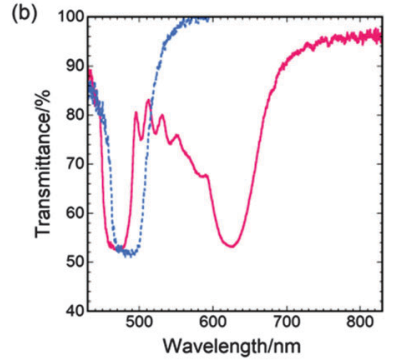

Fig. 6 (a) Variation of optical pitch with film depth for the CLC-1.5 (open circle) and CLC-2.5 (closed circle) films illuminated by UV light $\left(10 \mathrm{~mW} \mathrm{~cm}^{-2}\right.$, $300 \mathrm{~s})$ and for the CLC-2.5 film illuminated by UV light $\left(73 \mathrm{~mW} \mathrm{~cm}{ }^{-2}, 300 \mathrm{~s}\right)$ (closed triangle). (b) Transmission spectrum of the CLC-2.5 film before (broken line) and after (solid line) UV irradiation. 
variation of the polymerisation rate in UV-irradiated CLC films is expected if atmospheric oxygen is dissolved in the CLC and diffuses into the film during UV irradiation. Although oxygen dissolved in the CLC reacts with radicals generated by the UV-illuminated PI, unconsumed radicals can initiate the polymerisation. The $P$ at film depth greater than $10 \mu \mathrm{m}$ is not changed upon UV irradiation, even though the chiral dopant decreases the HTP via the photoreaction. This result suggests that the concentration of unconsumed radical is sufficiently high that the polymerisation rate is sufficiently rapid to maintain the original CLC configuration. In contrast, in the upper half of the film, the pitch increases with decreasing film depth, suggesting that the polymerisation rate decreases with decreasing film depth to allow the CLC to untwist. This behaviour is explainable if oxygen permeates into the film from the air interface. Radicals generated from UV-irradiated PI will react with permeated oxygen such that the effective concentration of radicals in the polymerisation decreases, resulting in a decrease in the polymerisation rate toward the air-interface side. In contrast, the photoreaction rate of the chiral dopant is independent of the film depth. Therefore, the pitch of the CLC increases with decreasing film depth. In contrast, irradiating UV-light on the same mixture between two glass slides only solidified the cholesteric LC without influence on both $\lambda_{0}$ and $\Delta \lambda$ of the reflection band.

The pitch profile of UV-irradiated CLC films depends on the PI concentration and the UV-light intensity. Fig. 6a shows the pitch profiles of UV-irradiated CLC films with different PI concentrations, where the films were irradiated under different powers but with the irradiation time held constant at $300 \mathrm{~s}$. When the CLC-2.5 and CLC-1.5 films were subjected to UV irradiation at the same intensity of $10 \mathrm{~mW} \mathrm{~cm}{ }^{-2}$, the $n P$ of the CLC-2.5 film decreased at the same film depth and reached the minimum pitch at a shallower depth compared with that of the CLC-1.5 film. This behaviour is attributed to the increase in the polymerisation rate due to the increase in PI concentration. As the UV intensity was increased from 10 to $73 \mathrm{~mW} \mathrm{~cm}^{-2}$, the pitch change in the CLC-2.5 film became sharper and the pitch reached its lowest value at a shallower film depth of $4 \mu \mathrm{m}$. The $n P$ decreased from $620 \mathrm{~nm}$ to $440 \mathrm{~nm}$ within a narrow filmdepth range from 3 to $4 \mu \mathrm{m}$, although the $n P$ decreased at the air interface within a film depth of less than $1 \mu \mathrm{m}$. The spectrum of the CLC film exhibited two distinct reflection bands at $\lambda_{0}=480$ and $610 \mathrm{~nm}$ (Fig. 6b), and the film itself exhibited a magenta colour, which is one of the subtractive primary colours. We thus obtained CLC films having two distinct reflection bands as well as a wide reflection band that vary with the PI concentration and the UV-light intensity. An increase in UV-light intensity increased the rates both of the polymerisation and of the chiral dopant photoreaction, and altered the cholesteric pitch profile into a two-step change. These changes may have resulted from the severe conflict between the film vitrification and the untwisting of the cholesteric helix.

A similar method was used to prepare a magenta-coloured CLC film using a mixture of LC242, another type of chiral dopant and Irg907. The chiral dopant A4OOC (Fig. 7a) increases (a)

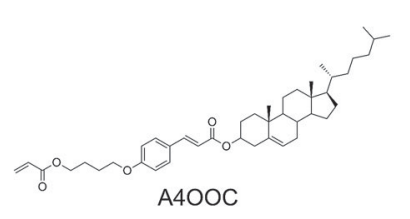

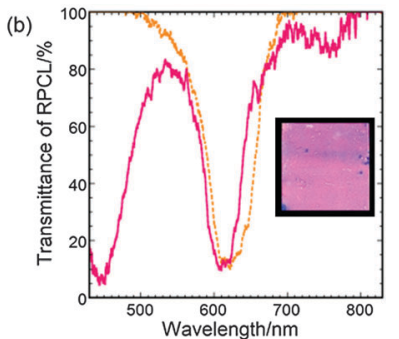

Fig. 7 (a) Chemical structure of the photoresponsive chiral dopant (A4OOC). (b) Transmission of right-handed circularly polarized light by the film of the chiral nematic liquid crystal of a 43.5/55/1.5 (w/w/w) mixture of LC242/A4OOC/Irg907 before (broken line) and after (solid line) irradiation with UV light $\left(50 \mathrm{~mW} \mathrm{~cm} \mathrm{~cm}^{-2}, 300 \mathrm{~s}\right)$. The inset shows the appearance of the film whose transmission spectrum is shown as the solid line.

HTP via the trans-to-cis photoisomerisation of the cinnamate moiety. ${ }^{15}$ Although the cholesteric film of a 43.5/55/1.5 (w/w/w) mixture of LC242, A4OOC and Irg907 at $70{ }^{\circ} \mathrm{C}$ exhibited a reflection peak at $\lambda_{0}=605 \mathrm{~nm}$, the transmittance spectrum of the film illuminated under UV light with an intensity of $50 \mathrm{~mW} \mathrm{~cm} \mathrm{~cm}^{-2}$ for $300 \mathrm{~s}$ showed two peaks at $\lambda_{0}=450 \mathrm{~nm}$ and $605 \mathrm{~nm}$ and the film exhibited a magenta colour, as shown in Fig. 7b. The chromaticity coordinates calculated from the transmittance spectrum were $x=$ 0.32 and $y=0.22$, indicating that the cholesteric colour was truly magenta. Thus, the atmospheric UV irradiation of CLCs of mixtures of a polymerisable LC monomer, PI and chiral dopant that changes the HTP via photoresponse provides an efficient method for preparing CLC films with broad and two distinct reflection bands that exhibit silver and the subtractive primary colour, respectively.

\section{Conclusions}

Planar-aligned CLC films with broad or two distinct reflection bands can be prepared by atmospheric UV irradiation of a mixture of a diacrylic nematic monomer, photoresponsive chiral dopant and PI. UV irradiation induces the photoreaction of the chiral dopant to change the HTP efficiently and photocleaves the initiator to generate radicals and initiate diacrylic monomer polymerisation. In such a way, UV-light illumination of the CLC film causes conflict between the pitch change and the freezing of the CLC structure. The polymerisation rate decreases with decreasing film depth because of atmospheric oxygen diffusing into the film and facilitating the change of the cholesteric pitch. The conflict becomes severe with increasing PI concentration and increasing UV-light power, resulting in a split of the reflection band into two distinct bands. Thus, this method can be used not only to broaden the reflection band to yield silver-coloured CLC films, but also to split the band to yield CLC films that assume a subtractive primary colour.

\section{Acknowledgements}

This study was supported by the Strategic Promotion of Innovative Research and Development from the Japan Science and Technology Agency, JST. 


\section{Notes and references}

1 W. Schlichting, S. Faris, B. Fan, J. Haag, Z. Lu, S. Kane, L. Li, T. Milster and H. Luo, Jpn. J. Appl. Phys., 1997, 36, 587-588.

2 V. I. Kopp, B. Fan, H. K. M. Vithana and A. Z. Genack, Opt. Lett., 1998, 23, 1707.

3 S. D. Jacobs, K. A. Cerqua, K. L. Marshall, A. Schmid, M. J. Guardalben and K. J. Skerrett, J. Opt. Soc. Am. B, 1988, 5, 1962.

4 N. Tamaoki, Adv. Mater., 2001, 13, 1135-1147.

5 J. Lub, P. van de Witte, C. Doornkamp, J. P. A. Vogels and R. T. Wegh, Adv. Mater., 2003, 15, 1420-1425.

6 J. Lub, W. P. M. Nijssen, R. T. Wegh, J. P. A. Vogels and A. Ferrer, Adv. Funct. Mater., 2005, 15, 1961-1972.

7 R. A. M. Hikmet and H. Kemperman, Nature, 1998, 392, 476-479.
8 D. J. Broer, J. Lub and G. N. Mol, Nature, 1995, 378, 467-469.

9 M. Mitov, Adv. Mater., 2012, 24, 6260-6276.

10 M. Mitov, A. Boudet and P. Sopéna, Eur. Phys. J. B, 1999, 8, 327-330.

11 S. H. Chen, J. C. Mastrangelo and R. J. Jin, Adv. Mater., 1999, 11, 1183-1186.

12 P. Van de Witte, M. Brehmer and J. Lub, J. Mater. Chem., 1999, 9, 2087-2094.

13 J. Lub, D. J. Broer, R. T. Wegh, E. Peeters and B. M. I. van der Zande, Mol. Cryst. Liq. Cryst., 2005, 429, 77-99.

14 M. Tokita, M. Itoh, K. Marumo, Y. Harada, S. Kang, K. Sakajiri and J. Watanabe, Liq. Cryst., 2013, 40, 900-905.

15 F.-M. Hsieh, H. Fang and J.-H. Liu, Chem. Lett., 2010, 39, 485-487. 